\title{
Therapeutic potential of gasotransmitters for cold stress-related cardiovascular disease
}

\author{
Haijian Sun ${ }^{1}$, Xiaowei $\mathrm{Nie}^{2}$, Kangying $\mathrm{Yu}^{3}$, Jinsong Bian ${ }^{4,5^{*}}$
}

\begin{abstract}
Growing evidence has shown that exposure to low ambient temperature poses a huge challenge to human health globally. Actually, cold stress is closely associated with a higher incidence of cardiovascular morbidity and mortality in winter or in cold regions. Cellular and molecular mechanisms underlying cardiovascular complications in response to cold exposure have yet to be fully clarified. Considering that cold exposure is an important risk of cardiovascular complications, it is necessary to clarify the molecular mechanism of cold stress-induced cardiovascular diseases and to develop effective intervention strategies. Hydrogen sulfide $\left(\mathrm{H}_{2} \mathrm{~S}\right)$, nitric oxide (NO), and carbon monoxide (CO) are wellknown gasotransmitters that are endogenously produced in many biological systems. Accumulating studies have demonstrated that these gasotransmitters play a critical role in a wide spectrum of physiological and/or pathophysiological processes by regulating numerous signaling pathways. These gas signal molecules are emerging as important players in cardiovascular homeostasis, and disruption of these gasotransmitters is critically implicated in cardiovascular anomalies, such as hypertension, atherosclerosis, myocardial ischemia, heart failure, and stroke. Also, evidence is emerging that $\mathrm{H}_{2} \mathrm{~S}, \mathrm{NO}$, and $\mathrm{CO}$ may be involved in the pathologies of cold stress-induced cardiovascular ailments. In this review, we aim to highlight and discuss the recent advances towards the development of gasotransmitters-based therapeutics for cold stressrelated cardiovascular pathogenesis. We believe that the effects of $\mathrm{H}_{2} \mathrm{~S}$, $\mathrm{NO}$, and $\mathrm{CO}$ on cardiovascular regulation under cold environment will attract tremendous interest in the near future as they serve as novel regulators of cardiovascular biology in cold environment.
\end{abstract}

Keywords

cold stress; cardiovascular diseases; hydrogen sulfide; nitric oxide; carbon monoxide

Received 8 October 2021, accepted 2 December 2021

\section{Introduction}

During the last decades, many epidemics are linked with climate fluctuations, such as increased cardiovascular mortality and respiratory illnesses due to heatwaves or cold stress ${ }^{[1-2]}$. Generally, thermoregulation is vital for the autonomic nervous system to cope with heat and cold stress ${ }^{[3]}$. Malfunction of the neural thermoregulatory mechanism or exposure to extreme temperatures that exceed the body's thermoregulatory capacity could lead to potentially life-threatening deviations from the normal body temperature ${ }^{[4-5]}$. It is estimated that the number of deaths caused by hypothermia is twice as frequent as deaths caused by hyperthermia ${ }^{[5]}$. Cold weather has a deleterious effect on human health, tolerance, and performance, such as decreases in deep body and muscle temperatures (Fig. 1$)^{[6]}$. The response
1 School of Traditional Chinese Pharmacy, China Pharmaceutical University, Nanjing 211198, China

2 Shenzhen Key Laboratory of Respiratory Diseases, Shenzhen People's Hospital (The First Affiliated Hospital, Southern University of Science and Technology), Shenzhen 518055, China

3 Nursing School of Wuxi Taihu University, Wuxi 214064, China

4 Department of Pharmacology, School of Medicine, Southern University of Science and Technology, Shenzhen 518055, China

5 National University of Singapore (Suzhou) Research Institute, Suzhou 215000, China

"Corresponding author Jinsong Bian, E-mail: bianjs@sustech.edu.cn of tissues to cold exposure can be acute, gradual, or chronic ${ }^{[7]}$. Acute effects are mainly thermoregulatory reflex mediated by the sympathetic nervous system (SNS), including immediate cardiovascular and respiratory responses ${ }^{[7]}$. The gradual effect is reflected by a gradual decrease in the temperature of peripheral or core tissues, leading to pain, neuromuscular insufficiency, loss of sensation, and eventually cold injury ${ }^{[7]}$. Chronic effects may affect peripheral nerves and blood vessels, as well as heart and lung functions ${ }^{[7]}$. In particular, deterioration of physiological functions in the elderly might increase the risk of the harmful effects of cold exposure ${ }^{[7]}$. Therefore, careful examination, practical measures and effective therapeutic approaches need to be developed and implemented to protect against cold stressrelated diseases among the elderly. 
It is commonly recognized that cardiovascular deaths are significantly increased during the cold season of the year ${ }^{[8-10]}$. Epidemiologic studies have established that the mortality from subjects suffering from ischaemic heart disease is correlated to the ambient temperature, especially in the winter ${ }^{[11]}$. Consistently, a systematic review and meta-analysis showed that the risk of cardiovascular hospitalization increases $2.8 \%$ for cold exposure ${ }^{[12]}$. Investigations on the relationship between temperature and coronary heart disease (CHD) have shown an increase in cardiac death as the temperature decreases ${ }^{[13-16]}$. The mortality in patients with $\mathrm{CHD}$ increases by approximately $1 \%$ per degree of fall in temperature below ${ }^{[17-18]}$. As is the case with CHD, the number of deaths in patients with cerebrovascular accidents is increasing with lowering environmental temperatures ${ }^{[18-22]}$. Overall, cold temperature is an important environmental factor for human life-threatening events, including cardiovascular and cerebrovascular diseases.

Cold exposure induces vasoconstriction and tachycardia with a concomitant rise in blood pressure and cardiac workload, creating deleterious effects on patients with ischaemic heart disease ${ }^{[23]}$. Cold temperature exacerbates high blood pressure and triggers cardiovascular complications, including stroke, myocardial infarction, cardiac hypertrophy and heart failure (Fig. 2) ${ }^{[24]}$. Thus, it is pressing to investigate how cold temperatures contribute to cardiovascular and cerebrovascular disorders. Several mechanisms are thought to account for the occurrence and development of cardiovascular disorders in cold temperature, including elevated blood pressure, hematological alterations, and respiratory tract infections ${ }^{[25]}$. Under cold circumstances, ischemia might happen with increased arterial blood pressure, followed by increased myocardial oxygen demand and decreased blood supply through coronary arteries ${ }^{[26-28]}$. Moreover, cold temperature can change blood composition and render a loss of plasma fluid ${ }^{[9]}$. These detrimental changes could explain the sudden thrombotic death in response to cold stress since they can predispose an individual to arterial thrombosis following the cold challenge $\mathrm{e}^{[9,29-30]}$. In addition, respiratory, viral, and bacterial infections, which frequently occur in the wintertime, might induce attacks of $\mathrm{CHD}$ or stroke due to their detrimental effects on the blood coagulating factors ${ }^{[31-32]}$.

Nitric oxide (NO), carbon monoxide (CO), and hydrogen sulfide $\left(\mathrm{H}_{2} \mathrm{~S}\right)$, three well-known gasotransmitters, play a fundamental role in numerous physiological and/or pathophysiological processes $^{[33]}$. The significance of gasotransmitters in human health and diseases has been well recognized for decades ${ }^{[34]}$. Failure of the gasotransmitter systems is believed to be responsible for the development of numerous diseases, including cardiovascular disorders ${ }^{[34]}$. Such gas signaling molecules have a tremendous potential as therapeutic targets for human disease. Coincidentally, accumulating evidence has suggested that these gasotransmitters are critically implicated in cardiovascular disorders induced by cold exposure ${ }^{[35-37]}$. In this review, we will recapitulate recent advances in the potential roles and mechanisms of gasotransmitters in cold-induced cardiovascular disorders and highlight the possible challenges and directions of gasotransmitters-based pharmacological therapy of the conditions.

\section{Current understanding of cold stress-related cardiovascular disorders}

There is a higher incidence in morbidity and mortality of cardiovascular diseases during the wintertime or prolonged periods of low temperature ${ }^{[38-39]}$. Consistent with this, a higher incidence of cardiac events is intimately related to the wintertime, such as angina, arrhythmias, dyspnea, acute myocardial infarction, stroke, and sudden cardiac death ${ }^{[9,38,40-46]}$. Increased mortality and morbidity from cardiovascular complications in winter has been documented in many countries ${ }^{[10]}$.

A direct link exists between low temperatures and cardiovascular complciations, and such a link is particularly strong in patients with cardiovascular disorders ${ }^{[38,47]}$. It is observed that patients with a family history of hypertension have a higher reactivity to the cold pressor test ${ }^{[48]}$. In untreated hypertensive patients, cold exposure temporarily could increase systolic blood pressure above $200 \mathrm{mmHg}^{[49]}$, suggesting that hypertension together with cold exposure likely increases the risk of cardiovascular events. Animal studies have revealed that continuous exposure to cold causes an obvious increase in blood pressure, tachycardia, and cardiac hypertrophy (Fig. 3) ${ }^{[50-52]}$. In addition, increased blood pressure in rats after cold treatment for 7 weeks failed to return to pre-cold exposure level even after discontinuing cold exposure for as long as 4 weeks ${ }^{[53]}$. As such, high blood pressure induced by a chronic exposure to cold stress may not be reversible after returning to the thermal neutral temperature. Likewise, intermittent exposure of rats to cold temperature also elevates blood pressure ${ }^{[54]}$. It is noteworthy that the elevated arterial blood pressure might be an adaptive response to cold exposure since the elevation of blood pressure can enhance circulatory function to promote non-shivering thermogenesis and metabolic rate ${ }^{[51,55]}$. Nevertheless, persistent high blood pressure is detrimental to targeted organs including heart, blood vessels, brain, and kidney ${ }^{[56-58]}$. Studies have indicated that the sympatho-adrenal system and the renin angiotensin system (RAS), endothelin-1 overproduction, and upregulation of mineralocorticoid receptors in the hypothalamus are involved in the development of hypertension induced by cold exposure ${ }^{[24,59-60]}$.

Coronary artery disease such as coronary artery disease (CAD) 


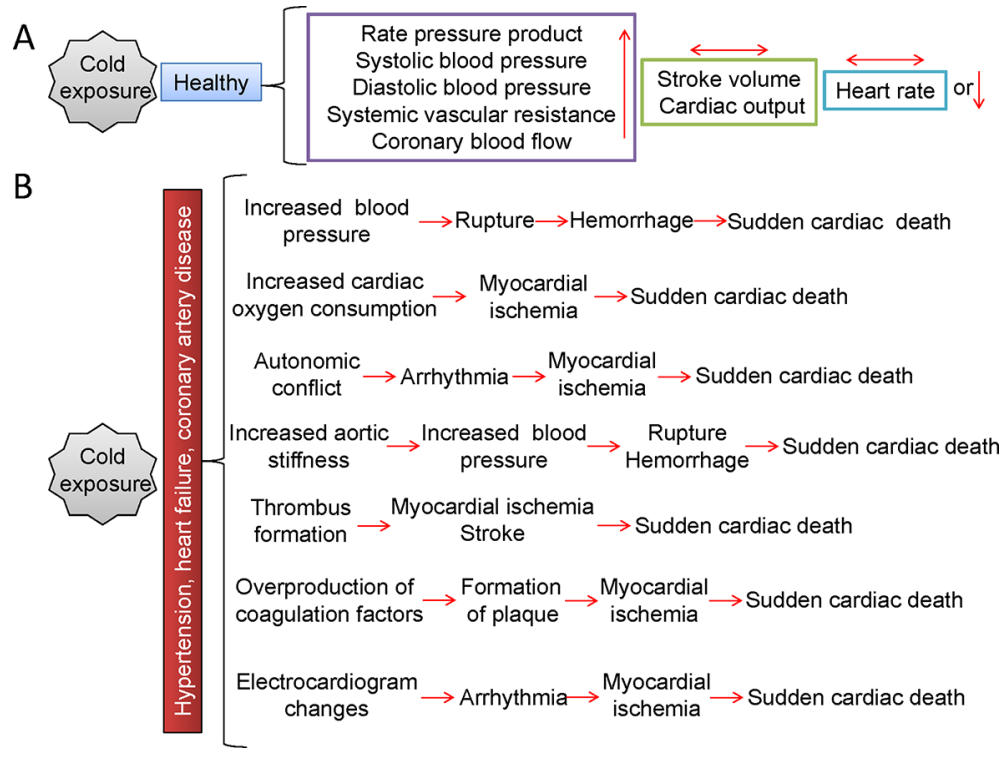

Fig. 1 Effects of cold temperature on cardiovascular response in heathy controls and patients with hypertension, heart failure, coronary artery disease

(A) In healthy controls, the cardiovascular responses are presented. (B) Cold induces dysregulation and increases the risk of cold-related cardiovascular events in subjects with hypertension, heart failure, and coronary artery disease.

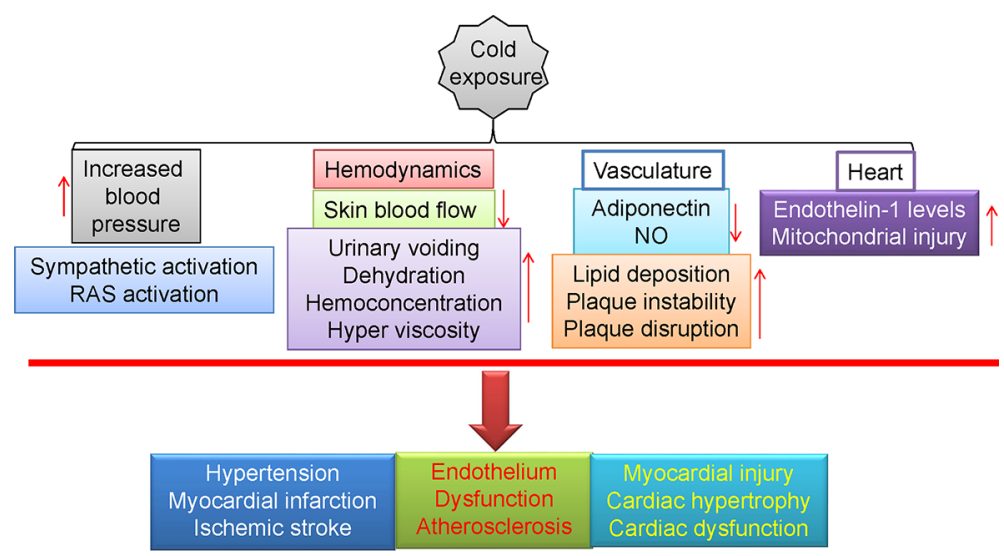

Fig. 2 The hypothesized mechanisms of cold exposure-induced cardiovascular disorders

(1) In response to cold exposure, activation of the sympathetic nervous system (SNS) and renin-angiotensin system (RAS) is responsible for elevation of blood pressure. (2) Cold-air exposure inhibits the skin blood flow due to the vasoconstriction, along with increased urine voiding, dehydration, hemoconcentration, and hyperviscosity. (3) Cold stress is associated with endothelial dysfunction, as evidenced by reductions in nitric oxide (NO) and adiponectin in the vascular system. In addition, cold environment contributed to atherosclerosis by enhancing lipid deposition, plaque instability, and plaque disruption. (4) Plasma levels of endothelin-1 levels are upregulated during cold stress, triggering mitochondria dysfunction in cardiomyocytes. All above changes induced by cold exposure could drive the development and progression of hypertension, myocardial infarction, ischemic stroke, atherosclerosis, cardiac hypertrophy and cardiac dysfunction. 


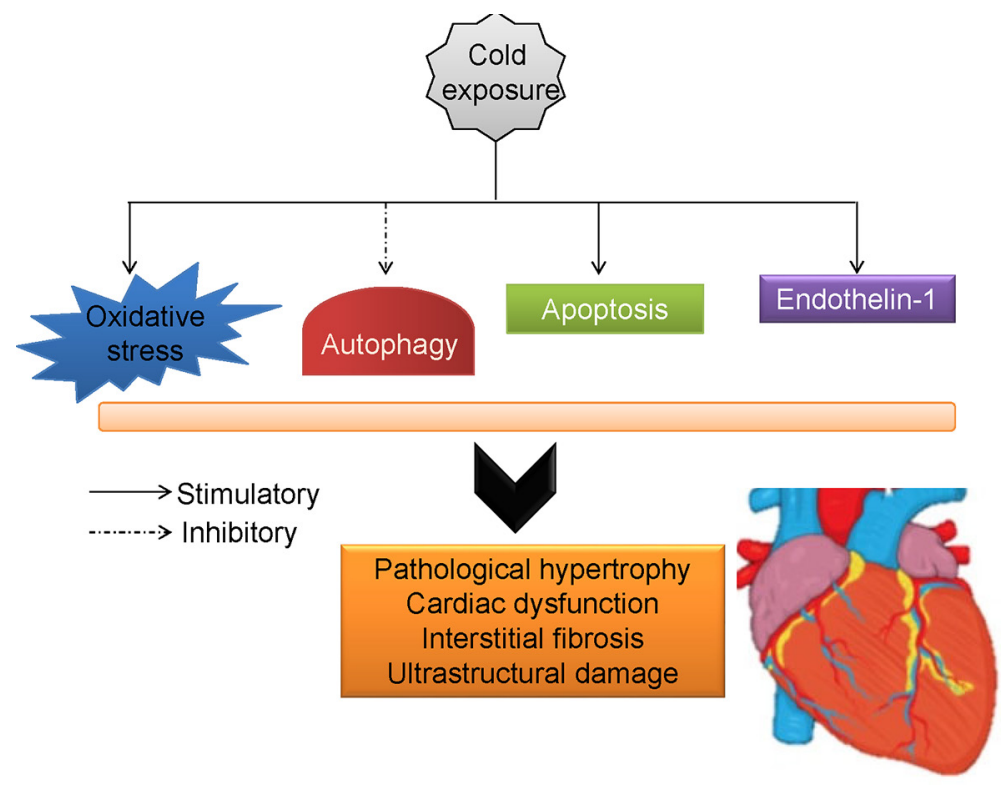

Fig. 3 A proposed mechanism of myocardial injury induced by cold stress

Abnormal changes in oxidative products, impaired autophagy processes, induction of apoptosis-related proteins, and increased level of endothelin-1 in myocardium could synergistically result in pathological hypertrophy, interstitial fibrosis, ultrastructural damage and cardiac dysfunction during cold exposure.

or coronary heart disease (CHD), also referred to as ischemic heart disease (IHD), can be manifested as stable angina, unstable angina and myocardial infarction ${ }^{[61]}$. It has been found that cold exposure accelerates the atherosclerotic plaque growth and instability in genetic models through uncoupling protein 1-dependent lipolysis and adiponectin reduction ${ }^{[62]}$. Reduction of blood flow to the heart can cause myocardial infarction and cardiac muscle damage. There is ample evidence that the wintertime is closely associated with greater incidences of angina ${ }^{[63]}$, myocardial infarction ${ }^{[64]}$ and sudden cardiac death ${ }^{[65]}$. Albeit similar trends towards elevated incidence of CAD in cold stress were observed, it is still disputable as whether CAD is associated with the cold pressor test. A study by Mudge et al. revealed comparable increases in blood pressure in response to the cold pressor test between patients with CAD and controls ${ }^{[66]}$. In keeping with this, the subjects with CAD had a similar hemodynamic response compared with those with structurally normal arteries ${ }^{[67]}$. Conversely, CAD patients complicated with chest pain have a higher cardiovascular response to the cold pressor test in comparison with those who have only chest pain ${ }^{[68]}$. The controversial results may be due to the lack of healthy controls. Therefore, more rigorous studies are required to assess the precise effects of cold stimulation on cardiovascular responses in patients with CAD, especially including healthy controls for comparison. One should keep in mind that CAD is usually related to a decrease in myocardial blood flow in a cold pressor test. This may give rise to (but not always) the appearance of angina associated with myocardial ischemia.

Heart failure, also known as congestive or chronic heart failure, is characterized by oedema, breathlessness, and fatigue because of potential abnormalities in heart function and structure ${ }^{[69-70]}$. Heart failure occurs when the heart is incapable of maintaining blood flow to meet the requirements of the body. The long-term progression of heart failure includes enlarged ventricles and atria, and pulmonary oedema ${ }^{[71]}$. Cold-induced vascular constriction is linked with increased cardiac afterload in which a failing heart might be incompetent to compensate by increasing the work of the heart ${ }^{[40]}$. Heart failure is one of the independent predictors of inpatient mortality in cold winter $^{[72]}$. Thomas and colleagues found that acute exposure to Finnish sauna and cold-water immersion produces comparable haemodynamic changes between patients with chronic heart failure and control subjects ${ }^{[73]}$. Yet, these results should be interpreted with caution because of short duration of cold immersion and small sample size. Overall, the evidence for coldrelated cardiovascular responses in patients with heart failure is still sparing. More comprehensive studies are warranted to identify potential therapeutics for cold stress-induced heart 


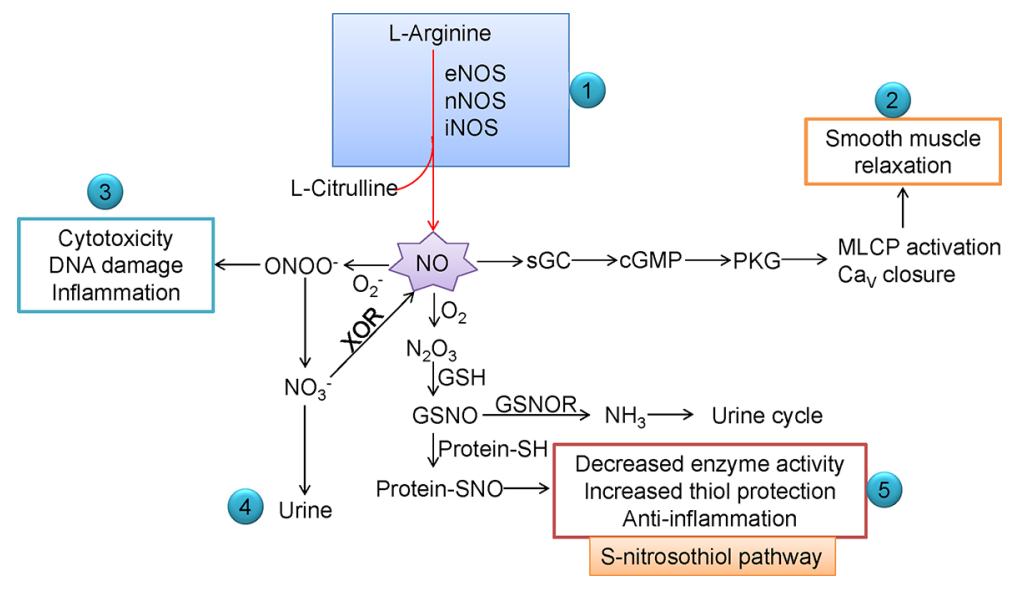

Fig. 4 Production and metabolism of NO

(1) The formation of NO is catalyzed by neuronal NOS (nNOS), endothelial NOS (eNOS), and inducible NOS (iNOS) from L-Arginine. (2) NO induces the relaxation of vascular smooth via sGC/cGMP signaling, followed by activation of PKG that phosphorylates several targets including MLCP and Cav. (3) During the cytotoxic pathway, NO reacts with superoxide anion to generate ONOO-, a strong oxidant that promotes DNA damage and inflammation. (4) The purine catabolic enzyme $\mathrm{XOR}$ could reduce $\mathrm{NO}_{3}-$ to $\mathrm{NO}$, and $\mathrm{NO}_{3}$ - could be scavenged through the urine route. (5) S-nitrosation is involved in NO signal transduction mechanisms. sGC, soluble guanylyl cyclase; cGMP, cyclic guanosine monophosphate; PKG, protein kinase G; MLCP, myosin light chain phosphatase; Cav, voltage-gated calcium (Ca2+) channels; XOR, xanthine oxidoreductase; NO, nitric oxide.

failure. Despite this well-known link between cold temperatures and high cardiovascular risk, the underlying mechanisms of coldinduced cardiovascular disorders are still poorly understood. Future work is highly required to shed light on the mechanisms that underlie cold-induced cardiovascular events to pave an avenue for the prevention and treatment of cold-associated cardiovascular disorders.

\section{Biogenesis of $\mathrm{NO}, \mathrm{CO}$, and $\mathrm{H}_{2} \mathrm{~S}$}

Although they had once been previously considered as toxic gases, $\mathrm{NO}, \mathrm{CO}$, and $\mathrm{H}_{2} \mathrm{~S}$, the members of gasotransmitter family ${ }^{[74]}$, have now been implicated in the modulation of a wide range of physiological and/or pathophysiological events in cardiovascular, nervous, gastrointestinal, respiratory, and immune systems through interacting with specific targets ${ }^{[75]}$. NO, $\mathrm{CO}$, and $\mathrm{H}_{2} \mathrm{~S}$ are endogenously produced, and they exert a myriad of biological effects at the physiological levels ${ }^{[76-78]}$. Since it was defined as an endothelium-derived relaxation factor in the 1980s, NO has been established as an important signaling molecule in the cardiovascular system ${ }^{[79]}$. CO was recognized as a gaseous regulator in the cardiovascular system a decade later ${ }^{[80]}$. Subsequently, $\mathrm{H}_{2} \mathrm{~S}$ was emerged as a signaling molecule akin to $\mathrm{NO}$ and $\mathrm{CO}^{[81]}$. Importantly, all gasotransmitters exhibit several critical actions to preserve cardiovascular homeostasis and health and hold great potential as therapeutic targets ${ }^{[82]}$.
Endogenous NO is generated by three nitric oxide synthase (NOS) enzymes, including neuronal NOS (nNOS), inducible NOS (iNOS), and endothelial NOS (eNOS) (Fig. 4) ${ }^{[83]}$. The NOS isoforms function as dimers to produce I-citrulline and $\mathrm{NO}$ by using I-arginine, $\mathrm{O}_{2}$, and $\mathrm{NADPH}$, as well as various cofactors ${ }^{[83]}$. Post-translational modification of NOS enzymes by phosphorylation of specific residues is an important way to regulate enzyme activity, making these enzymes sensitive to activation at lower $\mathrm{Ca}^{2+}$ concentrations ${ }^{[84-85]}$. Intracellular $\mathrm{Ca}^{2+}$ concentrations are necessary for the activation of NOS, with nNOS and eNOS demanding higher $\mathrm{Ca}^{2+}$ concentrations than iNOS $^{[86]}$. NO is known to induce vascular smooth muscle relaxation primarily through soluble guanylyl cyclase (sGC)/cyclic guanosine monophosphate (cGMP) signaling ${ }^{[86]}$. Subsequently, cGMP activates protein kinase G (PKG) that phosphorylates several targets, including myosin light chain phosphatase (MLCP) and voltage-gated calcium $\left(\mathrm{Ca}^{2+}\right)$ channels $(\mathrm{Cav})^{[87]}$. Closure of Cav reduces cytoplasmic $\mathrm{Ca}^{2+}$ entry, thereby reducing the binding of $\mathrm{Ca}^{2+}$ to calmodulin (CaM) and curtailing the activity of CaM-dependent myosin light chain kinase $(\mathrm{MLCK})^{[88]}$. Under the state of oxidative stress, the reaction between $\mathrm{NO}$ and superoxide anion yields peroxynitrite $\left(\mathrm{ONOO}^{-}\right)$, which limits downstream NO effects ${ }^{[86]}$. S-nitrosation is characterized by the addition of a nitroso group to the specific cysteine thiol, alongside the formation of S-nitrosothiol (SNO), and this posttranslational modification is the predominant process mediating NO signaling ${ }^{[89-90]}$.

Endogenous $\mathrm{CO}$ is a byproduct of heme degradation regulated 
by heme oxygenase (HO) (Fig. 5) ${ }^{[91]}$. HO-1, $\mathrm{HO}-2$, and $\mathrm{HO}-3$ are three isoforms of $\mathrm{HO}$. $\mathrm{HO}-1$ is ubiquitously expressed in most cells and induced by cellular stress ${ }^{[92]}$. HO-2 is abundantly expressed in hepatic, vascular, and neuronal tissues ${ }^{[93]}$. Although the HO-3 transcript is detectable in the spleen, prostate, heart, kidney, liver, thymus, brain, and testis, studies on the functions of HO-3 are largely lacking ${ }^{[94]}$. $\mathrm{HO}$ is mandatory for converting heme to $\mathrm{CO}$, biliverdin, and iron utilizing cytochrome P450 reductase as an electron donor ${ }^{[95]}$. During this process, biliverdin is further transformed to bilirubin through biliverdin reductase $\mathrm{e}^{[91]}$. Similar to NO, CO shares the same downstream sGC/cGMP signaling pathway ${ }^{[93]}$.

There are three enzymes known to yield $\mathrm{H}_{2} \mathrm{~S}$, including cystathionine $\beta$-synthase (CBS), cystathionine $\gamma$-lyase (CSE), and 3-mercaptopyruvate sulfur transferase (3-MST)/cysteine aminotransferase (CAT) (Fig. 6) ${ }^{[96]}$. Besides, $\mathrm{H}_{2} \mathrm{~S}$ can also be generated from $D$-cysteine through $D$-amino acid oxidase $(D A O)^{[97]}$. Apart from the enzymatic pathway, $\mathrm{H}_{2} \mathrm{~S}$ can be generated through non-enzymatical pathway or by bacteria ${ }^{[34]}$. In general, CBS and CSE are cytosolic enzymes, whereas 3-MST is primarily present in the mitochondria ${ }^{[98-99]}$. It is important to mention that $\mathrm{H}_{2} \mathrm{~S}$ exists in its anion form of $\mathrm{HS}-$, and it is estimated that HS- accounts for about $70 \%$ in $\mathrm{H}_{2} \mathrm{~S}$ / HS- mixture under physiological conditions ${ }^{[100]}$. This mixture is beneficial to drive persulfidation on cysteine residues of target proteins, a critical mechanism that underlies $\mathrm{H}_{2} \mathrm{~S}$-regulated biological functions ${ }^{[101-102]}$. Emerging evidence has suggested the therapeutic potential of gasotransmitters for cardiovascular disorders under cold environment.

\section{Role of NO in cold stress-related cardiovascular diseases}

Overreaction of systolic blood pressure to cold pressure test by increased sympathetic activity might be used to predict the progression of hypertension in young healthy adults ${ }^{[103-104]}$. The overweight individuals exhibit a greater sympathetic nerve reactivity to the cold pressure test compared to lean adults ${ }^{[105-106]}$. Since cold stimuli might increase myocardial workload and induce adverse cardiovascular events in susceptible subjects, therapies targeted to reduce cardiac afterload in response to cold stress could be cardioprotective $\mathrm{e}^{[107]}$. L-arginine serves as the substrate for the production of $\mathrm{NO}$, a well-known vasodilator. I-Citrulline is more potent and efficient than L-arginine in promoting NO release, and I-Citrulline treatment reduces blood pressure, wave reflection, and pulse wave velocity in middleaged patients with hypertension and arterial stiffness ${ }^{[108]}$, but not in healthy men $^{[109]}$. Yet, the possible role of I-Citrulline in vascular reactivity during cold stress in obese people remains unclear.
Arturo and colleagues demonstrated that administration of I-Citrulline impedes systolic blood pressure and arterial stiffness induced by cold challenge in overweight males, suggesting a protective effect of I-Citrulline against increased cardiac afterload in overweight men in cold stress environment ${ }^{[110]}$. Accordingly, the NO system is likely to be a predominant mediator in this nongenetic, nonpharmacological, nonsurgical model of hypertension.

Accumulating evidence suggests that cold exposure leads to elevated blood pressure and subsequent cardiovascular events $^{[111-112]}$. Activation of the RAS and SNS may participate in cold acclimation-induced hypertension ${ }^{[113-114]}$. The involvement of NO pathway in cold-evoked hypertension was confirmed by the finding that inhibition of NO by N omega-nitro-L-arginine caused increased blood pressure and heart rate in cold-exposed rats, indicating that NO plays a crucial role in the occurrence of cold-induced elevation of blood pressure ${ }^{[115]}$. Perturbation of endogenous NO is also highly relevant to cold stress-induced cardiovascular oscillations in hemodynamic changes since pretreatment with an NOS inhibitor L-NAME (NG-nitro-I-arginine methyl ester) significantly increased systolic blood pressure, heart rate, dicrotic notch, cardiovascular oscillations under cold environment ${ }^{[35]}$. Rats following 6 weeks of exposure to cold exhibited higher systolic blood pressure than control ones, with a concomitant decrease in NO contents in heart tissues ${ }^{[116]}$.

Compared with room temperature, cold exposure exacerbates vascular dysfunction through decreasing the expression of phosphorylated eNOS protein in aorta, and this could be blunted after the administration of atorvastatin, suggesting a protective role of atorvastatin against cold-induced hypertensive vascular dysfunction via regulation of NO signaling ${ }^{[117]}$. Consistently, the expression of eNOS in aortic tissues is substantially inhibited in cold-induced hypertensive rats ${ }^{[118]}$. The NOS activity is reduced by $19.1 \%$ in cold stress-damaged vessels relative to that in the control vessels ${ }^{[119]}$. Co-application of superoxide dismutase and vitamin $\mathrm{C}$ rescues the damaged vessels under cold stress, effects that are mediated by restoration of NOS activity ${ }^{[119]}$. Amlodipine reduces high blood pressure and lowers left ventricular weight index in cold stress-induced spontaneously hypertensive rats, and this may be related with a significant increase in blood NO concentration ${ }^{[120]}$.

Local cooling of the human fingers induces a rapid vasoconstriction, followed by cold-induced vasodilation in several minutes ${ }^{[121-122]}$, which is indispensable for protecting the cutaneous tissues against cold injury. Whilst the physiological reflex response of cold-induced vasoconstriction followed by vasodilatation is historically knowable, the underlying 


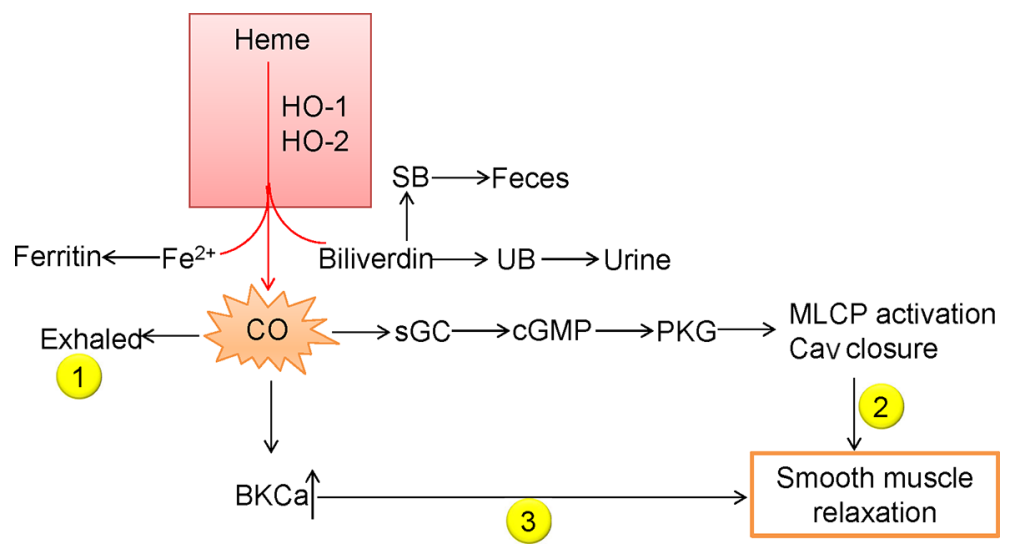

Fig. 5 Production and metabolism of CO. $\mathrm{HO}-1$ and $\mathrm{HO}-2$ enzymes are able to degrade heme to yield $\mathrm{CO}$, iron, and biliverdin

(1) Excessive CO could be exhaled from the mammalian lungs. (2) In the classical pathway, CO is mechanistically identical to NO signaling, that is, CO activates the sGC/cGMP/ PKG pathway that elicits smooth muscle relaxation. (3) Also, CO binds to heme groups of (BKCa) and increases BKCa channel opening, this can also cause smooth muscle relaxation. $\mathrm{HO}$, heme oxygenase; $\mathrm{CO}$, carbon monoxide; sGC, soluble guanylyl cyclase; cGMP, cyclic guanosine monophosphate; PKG, protein kinase G; MLCP, myosin light chain phosphatase; Cav, voltage-gated calcium $\left(\mathrm{Ca}^{2+}\right)$ channels; $\mathrm{NO}$, nitric oxide; $\mathrm{BKCa}, \mathrm{Ca}^{2+}$-gated large conductance $\mathrm{K}+$ channels.

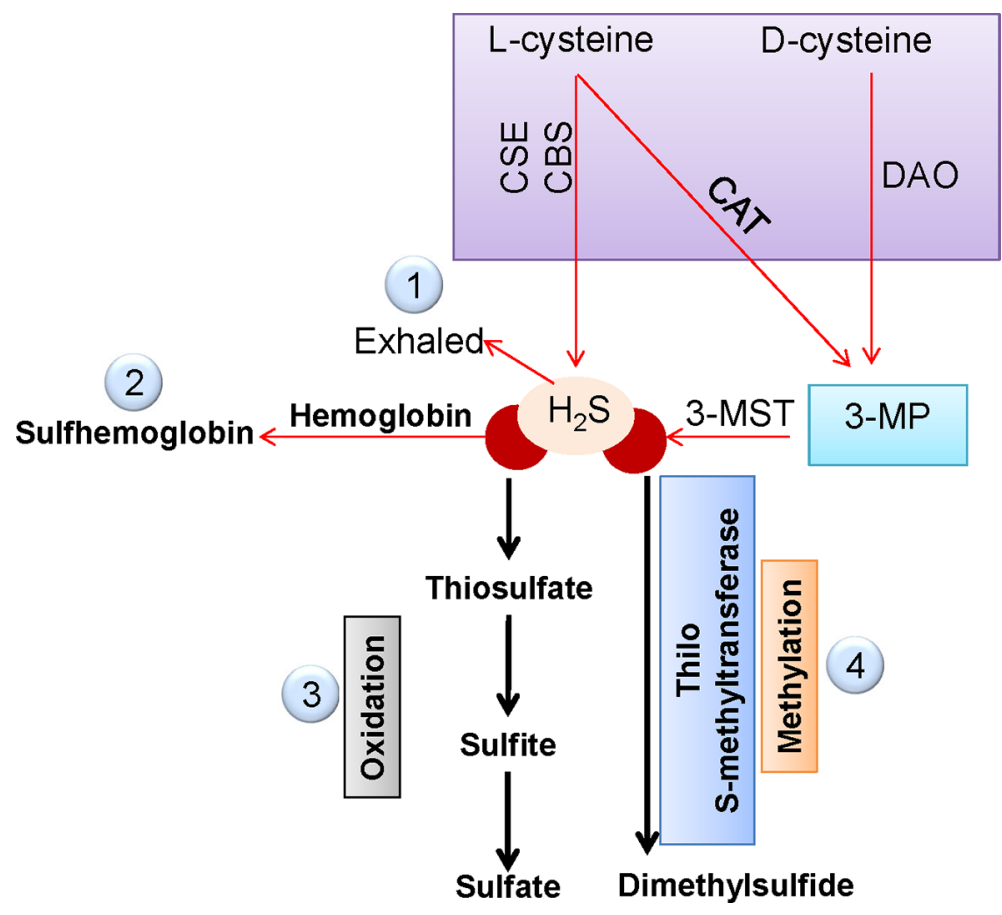

Fig. 6 Production and metabolism of $\mathrm{H} 2 \mathrm{~S}$

Three enzymes can enzymatically produce $\mathrm{H}_{2} \mathrm{~S}, \mathrm{CBS}$, CSE and 3-MST. With the aid of L-cysteine, CBS and CSE produce $\mathrm{H}_{2} \mathrm{~S}$. In an alternative pathway, 3-mercaptopyruvate could be produced by CAT using L-cysteine and DAO using D-cysteine, respectively. Then, 3-MST could generate $\mathrm{H}_{2} \mathrm{~S}$ using 3-MP as the substrate.

(1) $\mathrm{H}_{2} \mathrm{~S}$ could be exhaled. (2) Interaction of hemoglobin with $\mathrm{H}_{2} \mathrm{~S}$ results in the production of sulfhemoglobin. (3) $\mathrm{H}_{2} \mathrm{~S}$ is oxidized to thiosulfate, together with the formation of sulfite and sulfate. (4) $\mathrm{H}_{2} \mathrm{~S}$ is methylated into dimethylsulfide by thiol S-methyltransferase. $\mathrm{H}_{2} \mathrm{~S}$, hydrogen sulfide; CBS, cystathionine $\beta$-synthase; CSE, cystathionine $\mathrm{\gamma}$-lyase; 3-MST 3-mercaptopyruvate sulphurtransferase; 3-MP, 3-mercaptopyruvate; CAT, cysteine aminotransferase; DAO, D-amino acid oxidase. 
mechanisms are not clear. Susan's group unraveled that transient receptor potential ankyrin 1 (TRPA1) acts as a primary vascular cold sensor as the initial cold-induced vasoconstriction is mediated via TRPA1-dependent superoxide production, while the subsequent vasodilatation is also relied on TRPA1 activation which is mediated by sensory nerve-derived dilator neuropeptides calcitonin gene-related peptide (CGRP) and substance $\mathrm{P}$, and nNOS-derived NO as well ${ }^{[123]}$. These results shed light on the importance of TRPA1 in cold exposureinduced vascular response and provide impetus for further research into the importance of the NO system in the vascular response to environmental cold exposure. The activation of eNOS can be triggered by various mechanical forces, such as shear stress ${ }^{[124-125]}$. An interesting study documented that low temperature alone does not affect eNOS expression, whereas the combination of shear stress with low temperature $\left(4^{\circ} \mathrm{C}\right)$ inactivates $\mathrm{NO}$ in endothelial cells ${ }^{[126]}$. These results suggest that the endothelial cells-derived NO plays a critical role in blood vessel regulation under shear stress and cold temperature. These studies suggest that endogenous NO plays a critical role in mediating the effects of cold stress on autonomic cardiovascular regulation, and enhanced NO production appears to be a compensatory process to prevent the blood pressure response from shifting to a higher level of sympathetic nerve activation and blood flow after a cooling challenge. Future studies aimed at identifying the roles and mechanisms of the endogenous NO system could be useful to extend and deepen our understanding of this gasotransmitter in cold-induced hypertension.

Several studies have shown that inactivation of the RAS attenuates or prevents cold-induced hypertension ${ }^{[52,127-129]}$. Angiotensinogen is the only known substrate for renin that is a rate-limiting enzyme of the RAS, and antisense oligodeoxynucleotides to angiotensinogen decreases blood pressure in cold-exposed rats ${ }^{[130]}$. Sun and coworkers examined the effects of angiotensinogen gene knockout on the development of cold-induced hypertension and cardiac hypertrophy in angiotensinogen gene knockout (Agt-KO) mice with chronic exposure to cold ${ }^{[59]}$. Results showed that the coldinduced increase in blood pressure was attenuated in Agt-KO mice $^{[59]}$. Further studies disclosed a significant increase in NO production in Agt-KO mice compared to that in wild-type mice ${ }^{[59]}$, suggesting that chronic cold exposure leads to diminished NO generation partially by activating the RAS. Similar to the findings observed in Agt-KO mice, AT1A receptor gene knockout (AT1A$\mathrm{KO})$ mice were resistant to hypertension after cold exposure, paralleling the significant increases in urine and plasma NO levels, implying that the activation of the RAS might inhibit NO generation possibly via AT1A receptors ${ }^{[131]}$. These findings indicate that the activation of the NO system might be helpful to prevent or treat cold-induced hypertension. Wang et al. evaluated the direct role of the NO system in cold-induced hypertension by delivering the adenovirus carrying human eNOS full-length cDNA into the rats housed under cold conditions and found that eNOS gene transferred-rats did not develop hypertension after exposure to cold ${ }^{[132]}$. Increases in the plasma and urine NO levels were detected in cold-exposed rats after eNOS gene transfer, which is accompanied by decreases in the plasma levels of norepinephrine and plasma renin activity ${ }^{[132]}$. This study provides robust evidence that NO attenuates coldinduced hypertension through blocking the SNS and RAS ${ }^{[132]}$.

The hypothalamic-pituitary-adrenal axis and the SNS are both stimulated under stress conditions, including acute cold stress. A study by Laila revealed that acute cold stress increases plasma triglycerides, glucose, and tissue plasminogen activator, as well as adrenomedullin levels in plasma, heart, and kidney tissues of rats ${ }^{[133]}$. By contrast, these hormonal and metabolic changes caused by cold exposure are abolished by vitamin $\mathrm{E}$ treatment or L-arginine treatment ${ }^{[133]}$. Given the antioxidative property of vitamin E and NO-releasing property of L-arginine, it is speculated that oxidative stress and NO dysfunction might be responsible for the metabolic and hormonal changes after acute cold stress. It is well documented that the blood flow in interscapular brown adipose tissue (IBAT) is accelerated in response to cold exposure. Korac and colleagues found that the capillary volume density and capillary-to-brown adipocytes ratio are augmented in rats exposed to cold temperature, an effect that is further increased by L-arginine treatment but decreased by L-NAME treatment ${ }^{[134]}$. Compared to respective controls, L-arginine-treated rats exhibited higher levels of eNOS expression and nitrotyrosine immunoreaction in IBAT, suggesting that NO has a key role in the remodeling process of the IBAT capillary network by angiogenesis ${ }^{[134]}$.

\section{Role of $\mathrm{CO}$ in cold stress-related cardiovascular diseases}

A plethora of studies have uncovered the importance of $\mathrm{CO}$ in the immune, respiratory, reproductive, gastrointestinal, renal, and hepatic systems ${ }^{[135]}$. CO is reported to lower blood pressure, relax vascular tissues, and protect the heart from ischemia/reperfusion injury $^{[76]}$. Abnormalities in $\mathrm{CO}$ metabolism and function are also linked to the pathogenesis of neurodegenerations, hypertension, heart failure, and inflammation ${ }^{[135]}$. Direct delivery of exogenous $\mathrm{CO}$ and enhancement of endogenous $\mathrm{CO}$ production are both rational and vivid strategies for clinical applications of $\mathrm{CO}$ replacement therapy for the prevention and treatment of coldinduced cardiovascular disease ${ }^{[136-137]}$. 
At $25^{\circ} \mathrm{C}$, central hypoxia does not suppress respiratory activity in conscious rats ${ }^{[138]}$. In sharp contrast, the ratio of ventilation and $\mathrm{O}_{2}$ uptake, and the ventilatory responses to ambient hypoxia and hypercapnia are significantly upregulated in rats with cold stress ${ }^{[138]}$. Pulmonary hypertension is a common presentation in patients with progressive systemic sclerosis (PSS $)^{[139]}$. Wise and coworkers determined the effects of cold-induced Raynaud's phenomenon on CO diffusing capacity (Dco) in patients suffering from Raynaud's phenomenon ${ }^{[139]}$. They found that cold exposure evoked an increase in Dco in patients without PSS, suggesting that patients with PSS had an altered pulmonary vascular response to cold exposure ${ }^{[139-140]}$. Application of exogenous 5-aminolevulinic acid (ALA) yields a significant protective effect against cold stress in soybean plants compared to non-ALA-treated plants, as evidenced by enhanced chlorophyll content and relative water content and decreased thiobarbituric acid reactive species levels ${ }^{[141]}$. More importantly, pretreatment with ALA enhances the activities of catalase and $\mathrm{HO}-1$, two known antioxidant enzymes ${ }^{[141]}$. This finding provides a piece of supporting evidence that ALA may be effective in protecting soybean plants from cold stress-induced damages by promoting heme catabolism, along with the formation of biliverdin and $\mathrm{CO}^{[141]}$.

It should be emphasized that an outbreak of $\mathrm{CO}$ poisoning after a major ice storm or a winter storm has been reported in Maine, Kingston, or Missouri of USA ${ }^{[142]}$. Notably, injuries from storm-related damage and $\mathrm{CO}$ intoxication are predominated in the 2002 North Carolina ice storm ${ }^{[142]}$. Indeed, many clinicians are concentrating on reducing the morbidity and mortality of patients who suffer from CO poisoning in medical practices ${ }^{[143]}$. Studies on the reduction of the complications and sequelae of $\mathrm{CO}$ poisoning are still being actively carried out ${ }^{[144-145]}$. As such, the application of $\mathrm{CO}$ to the treatment of human diseases may be counterintuitive and render a hesitation in applying $\mathrm{CO}$ as a treatment approach for patients. One of the most important limitations of $\mathrm{CO}$ medical applications is the lack of accurate monitoring methods for $\mathrm{CO}$ concentrations in tissues. Moreover, there are still few studies on the effect of hypothermia and hypoxia $(\mathrm{CO})$ on the development and progression of cardiovascular diseases. We admit that excessive CO exposure can damage numerous organs, including the cardiovascular system under normal temperature, hot or cold environment. Yet, whether low-doses or physiological doses of $\mathrm{CO}$ could protect against cold-induced cardiovascular diseases is worthy of further studies as low doses of CO offer anti-inflammatory, anti-oxidant, and anti-apoptotic effects ${ }^{[146]}$. In parallel with this, it merits indepth examination on whether modulation of endogenous $\mathrm{CO}$ system is beneficial for cardiovascular disorders under cold circumstances.

\section{Role of $\mathrm{H}_{2} \mathrm{~S}$ in cold stress-related cardiovascular diseases}

The protective roles of $\mathrm{H}_{2} \mathrm{~S}$ in many cardiovascular disorders have been well documented in several review papers, including ischemic myocardium, hypertension, myocardial ischemia-reperfusion, heart failure, stroke, and atherosclerosis ${ }^{[96-97,100,147-153]}$. Compelling evidence suggests that malfunction of endogenous $\mathrm{H}_{2} \mathrm{~S}$ system is detected in tissues or cells related to cardiovascular disorders since downregulation of endogenous $\mathrm{H}_{2} \mathrm{~S}$ content induces multiple deleterious events involved in the pathogenesis of cardiovascular disorders ${ }^{[151]}$. By contrast, supplementation of exogenous $\mathrm{H}_{2} \mathrm{~S}$ donors could effectively ameliorate the pathological process of cardiovascular diseases ${ }^{[153]}$. With respect to the underlying molecular mechanisms involved in $\mathrm{H}_{2} \mathrm{~S}$-mediated cardiovascular protection, $\mathrm{H}_{2} \mathrm{~S}$ has been found to regulate a variety of intricate mediators related to cardiovascular pathophysiology, including anti-oxidative, anti-apoptotic, antiinflammatory, and anti-necrotic factors ${ }^{[154]}$. Because of the powerful protective effects of $\mathrm{H}_{2} \mathrm{~S}$ in the cardiovascular system, it has become a promising candidate for the prevention and treatment of cardiovascular diseases ${ }^{[155-156]}$. Nevertheless, further research is necessary to better understand how to achieve the precision control of exogenous and endogenous $\mathrm{H}_{2} \mathrm{~S}$ in different cardiovascular diseases.

Heart transplantation is regarded as the standard treatment for advanced heart failure ${ }^{[157]}$. However, the heart could only be stored for 4 to $6 \mathrm{~h}$ in a cold static storage solution due to its vulnerability to ischemia-reperfusion injury ${ }^{[157]}$. Additionally, prolonged ischemic time has an unfavorable effect on the long-term survival rate of the graft $^{[157]}$. Accordingly, there is an urgent, unmet medical demand for the development of novel strategies for preserving the donor heart in a lowtemperature environment. To this end, Zheng's group explored whether $\mathrm{H}_{2} \mathrm{~S}$ protects cardiac grafts from sustained ischemia at subnormothermic temperatures and they found that AP39, a mitochondria-targeting $\mathrm{H}_{2} \mathrm{~S}$ donor, remarkably protected heart graft function against continuous cold ischemia-reperfusion injury $\left(24 \mathrm{~h}\right.$ at $\left.4^{\circ} \mathrm{C}\right)$, along with reductions in cardiac injury and fibrosis in a murine heart transplant model ${ }^{[158]}$. This study confirms that supplementation with AP39 confers a protection against ischemia-reperfusion injury in heart transplant. Increased rates of delaying the graft functional declining and early graft loss induced by prolonged ischemia-reperfusion injury might be effectively retarded in the presence of $\mathrm{H}_{2} \mathrm{~S}$. Likewise, administration of $\mathrm{H}_{2} \mathrm{~S}$ donors protects renal grafts from prolonged cold ischemia-reperfusion injury via keeping mitochondrial integrity and function, highlighting the therapeutic potential of $\mathrm{H}_{2} \mathrm{~S}$ in minimizing the detrimental clinical outcomes 
of prolonged cold renal ischemia-reperfusion injury during renal transplantation ${ }^{[159-161]}$. Collectively, $\mathrm{H}_{2} \mathrm{~S}$ supplementation might be a new strategy for organ preservation against ischemiareperfusion injury during the organ transplantation.

Although $\mathrm{H}_{2} \mathrm{~S}$ may be beneficial for heart transplantation-related ischemia-reperfusion injury in chilled environments, the direct roles of $\mathrm{H}_{2} \mathrm{~S}$ in cold stress-evoked cardiovascular complications remain largely unknown. Studies highlighted the dominant roles of $\mathrm{H}_{2} \mathrm{~S}$ in the pathogenesis of hypertension, atherosclerosis, myocardial ischemia, heart failure, and stroke ${ }^{[150,162-164]}$. Importantly, cold temperature activates the SNS and RAS, stimulates the production of endothelin-1, but diminishes eNOS-derived NO production, which are closely related to the occurrence and development of cardiovascular diseases ${ }^{[24]}$. These finding prompted us to propose that disruption of the endogenous $\mathrm{H}_{2} \mathrm{~S}$ system might be an etiology of cardiovascular disease. Future studies are needed to delineate the exact roles and potential mechanisms of $\mathrm{H}_{2} \mathrm{~S}$ in cold exposureassociated cardiovascular disease and to boost up the therapeutic applications of $\mathrm{H}_{2} \mathrm{~S}$ in cold medicine.

\section{Concluding remarks}

An increasing number of extreme weather events are taking place with increasing intensity and frequency with ever-changing climate. Correspondingly, ambient temperature challenges have direct effects on cardiovascular disease mortality and morbidity. It is commonly accepted that cold temperature exposure is associated with higher incidences of hypertension and related cardiovascular diseases, including stroke and myocardial infarction. Cold temperatures-triggered myocardial infarction and stroke are largely ascribed to cold-induced hypertension. To date, there are no specific interventions recommended for cold-induced hypertension. Disturbances in the metabolism of $\mathrm{NO}, \mathrm{CO}$, and $\mathrm{H}_{2} \mathrm{~S}$ play a central role in the pathologies of cardiovascular disease. Over the past decades, we have come to realize that all gasotransmitters are irreplaceable in a wide range of physiological or pathophysiological processes. Evidence is emerging that these gaseous signaling molecules play a direct role in the pathological processes of cold-induced cardiovascular diseases. Unfortunately, such evidence is still insufficient. In addition, when and how to use these gasotransmitters in the clinical management of cold-related cardiovascular diseases is an open question. The differences of the effects produced by these gasotransmitters on cold-related cardiovascular diseases also need to be elucidated and clarified.

Studies have shown gender differences in thermoregulatory response to cold stress ${ }^{[165]}$. In the cold water studies, women could cool down faster than men at rest in general, and intriguingly, such an abrupt change does not produce a greater metabolic response in women ${ }^{[165]}$. On the other hand, men exhibit a greater blood pressure response than women after a local cooling of hands or the face ${ }^{[165]}$. It is likely that women are less thermally sensitive to cold water stimulation ${ }^{[165]}$. A national time-series analysis has revealed that the relative risk of death from cardiovascular diseases was higher for men than for women at cold temperatures ${ }^{[166]}$. Despite these intriguing results, our understanding of the distinct responses to cold stress between men and women is still in its infancy. It remains to be answered whether the abnormalities in endogenous gas signal molecules contribute to the differences in thermal, metabolic, and cardiovascular alterations between men and women towards cold stress.

Current evidence suggests a potential role of gasotransmittersderived interventions for the treatment of cold-induced cardiovascular disorders. Although NO-, $\mathrm{CO}$-, and $\mathrm{H}_{2} \mathrm{~S}$-based drugs have tremendously advanced our understanding of cardiovascular disease intervention strategies, translation from cellular and animal models into clinical practice remains challenging. Of note, NO-, CO-, and $\mathrm{H}_{2} \mathrm{~S}$-based therapeutics on cold-related cardiovascular disorders in humans are very rare. Meanwhile, no research has adopted a holistic approach to measure the NO, $\mathrm{CO}$, and $\mathrm{H}_{2} \mathrm{~S}$ signaling pathways in the same experiment. In light of the sophisticated interactions between these gasotransmitters, the effects of gas transmitters-derived interventions (alone or in combination) are extremely difficult to predict.

For decades, cold stress and hypoxia are inseparable, and humans often encounter these stressors at high altitude ${ }^{[167]}$. Given that cold stress induces thermoregulatory and cardiovascular adjustments to retain body homeostasis, hypoxia is believed to influence multiple pathways related to autonomic thermoregulation during cold stress ${ }^{[167]}$. A combined exposure to hypoxia and the cold might exert more negative effects on autonomic and behavioral thermoregulatory and cardiovascular responses ${ }^{[168]}$. Future research is poised to identify whether and how human body maintains cardiovascular homeostasis in response to cold stress and hypoxia through regulation of endogenous gasotransmitters.

With the rapid advances in gasotransmitter research, we are optimistic that the pathogenesis of cold-induced cardiovascular diseases will become one of the important directions for future research on gas signaling molecules, and it will also provide a new perspective in the biology and pharmacology of $\mathrm{NO}, \mathrm{CO}$ and $\mathrm{H}_{2} \mathrm{~S}$. Devoting more efforts and resources to basic mechanisms of gasotransmitters could provide better information for clinical trials, thereby advancing the novel approaches for the prevention and treatment of cold-induced cardiovascular diseases based on gas signaling molecules. 


\section{Conflicts of interests}

Jinsong Bian is an Editorial Board Member of the journal. The article was subject to the journal's standard procedures, with peer review handled independently of this member and his research groups.

\section{Acknowledgments}

This work was supported by Ministry of Education of Singapore

Tier 2 Research grant (MOE2017-T2-2-029) and China Jiangsu

Nature Science Foundation (BK20181185).

\section{References}

[1] Patz J A, Campbell L D, Holloway T, et al. Impact of regional climate change on human health. Nature, 2005; 438(7066): 310-317.

[2] Bezirtzoglou C, Dekas K, Charvalos E. Climate changes, environment and infection: facts, scenarios and growing awareness from the public health community within Europe. Anaerobe, 2011; 17(6): 337-340.

[3] Tansey E A, Johnson C D. Recent advances in thermoregulation. Adv Physiol Educ, 2015; 39(3): 139-148.

[4] Nakamura K. Central circuitries for body temperature regulation and fever. Am J Physiol Regul Integr Comp Physiol, 2011; 301(5): R12071228.

[5] Cheshire W P. Thermoregulatory disorders and illness related to heat and cold stress. Auton Neurosci, 2016; 196: 91-104.

[6] Castellani J W, Tipton M J. Cold stress effects on exposure tolerance and exercise performance. Compr Physiol, 2015; 6(1): 443-469.

[7] Holm R I. Strategies for prevention of cold stress in the elderly. Int J Circumpolar Health, 2000; 59(3-4): 267-272.

[8] Näyhä S. Environmental temperature and mortality. Int J Circumpolar Health, 2005; 64(5): 451-458.

[9] Keatinge W R, Donaldson G C. Cardiovascular mortality in winter. Arctic Med Res, 1995; 54(Suppl 2): 16-18.

[10] Mercer J B. Cold-an underrated risk factor for health. Environ Res, 2003; 92(1): 8-13.

[11] Strand B H, Tverdal A. Can cardiovascular risk factors and lifestyle explain the educational inequalities in mortality from ischaemic heart disease and from other heart diseases? 26 year follow up of 50,000 Norwegian men and women. J Epidemiol Community Health, 2004; 58(8): 705-709.

[12] Phung D, Thai P K, Guo Y, et al. Ambient temperature and risk of cardiovascular hospitalization: an updated systematic review and metaanalysis. Sci Total Environ, 2016; 550: 1084-1102.

[13] Baker B A. Winter weather and cardiovascular mortality in Minneapolis-St. Paul. Am J Public Health, 1982; 72(3): 261-265.

[14] Schumann B, Erling H L, Karlsson L. Weather extremes and perinatal mortality-seasonal and ethnic differences in northern Sweden, 1800-1895. PloS One, 2019; 14(10): e0223538.

[15] Eng H, Mercer J B. Seasonal variations in mortality caused by cardiovascular diseases in Norway and Ireland. J Cardiovasc Risk, 1998; 5(2): 89-95.

[16] Wang B, Chai G, Sha Y, et al. Impact of ambient temperature on cardiovascular disease hospital admissions in farmers in China's Western suburbs. Sci Total Environ, 2021; 761: 143254.
[17] Danet S, Richard F, Montaye M, et al. Unhealthy effects of atmospheric temperature and pressure on the occurrence of myocardial infarction and coronary deaths. A 10-year survey: the lille-world health organization MONICA project (monitoring trends and determinants in cardiovascular disease). Circulation, 1999; 100(1): E1-E7.

[18] The Eurowinter Group. Cold exposure and winter mortality from ischaemic heart disease, cerebrovascular disease, respiratory disease, and all causes in warm and cold regions of Europe. The Eurowinter Group. Lancet, 1997; 349(9062): 1341-1346.

[19] Bull G M, Morton J. Environment, temperature and death rates. Age Ageing, 1978; 7(4): 210-224.

[20] Donaldson G C, Tchernjavskii V E, Ermakov S P, et al. Winter mortality and cold stress in Yekaterinburg, Russia: interview survey. BMJ, 1998; 316(7130): 514-518.

[21] Pan W H, Li L A, Tsai M J. Temperature extremes and mortality from coronary heart disease and cerebral infarction in elderly Chinese. Lancet, 1995; 345(8946): 353-355.

[22] Rogot E, Padgett S J. Associations of coronary and stroke mortality with temperature and snowfall in selected areas of the United States, 1962-1966. Am J Epidemiol, 1976; 103(6): 565-575.

[23] Näyhä S, Hassi J. Cold and mortality from ischaemic heart disease in northern Finland. Arctic Med Res, 1995; 54(Suppl 2): 19-25.

[24] Sun Z. Cardiovascular responses to cold exposure. Front Biosci, 2010; 2: 495-503.

[25] Näyhä S. Cold and the risk of cardiovascular diseases. A review. Int J Circumpolar Health, 2002; 61(4): 373-380.

[26] Stout R W, Crawford V. Seasonal variations in fibrinogen concentrations among elderly people. Lancet, 1991; 338(8758): 9-13.

[27] Neild P J, Stndercombe C D, Keatinge W R, et al. Cold-induced increases in erythrocyte count, plasma cholesterol and plasma fibrinogen of elderly people without a comparable rise in protein $\mathrm{C}$ or factor $\mathrm{X}$. Clin Sci, 1994; 86(1): 43-48.

[28] Lloyd E L. The role of cold in ischaemic heart disease: a review. Public Health, 1991; 105(3): 205-215.

[29] Donldson G C, Keatinge W R. Early increases in ischaemic heart disease mortality dissociated from and later changes associated with respiratory mortality after cold weather in south east England. $J$ Epidemiol Community Health, 1997; 51(6): 643-648.

[30] Donldson N G C, Robinson D, Allaway S L. An analysis of arterial disease mortality and BUPA health screening data in men, in relation to outdoor temperature. Clin Sci, 1997; 92(3): 261-268. 
[31] Bainton D, Jones G R, Hole D. Influenza and ischaemic heart disease--a possible trigger for acute myocardial infarction? Int $\mathrm{J}$ Epidemiolo, 1978; 7(3): 231-239.

[32] Syrj N J. Is there a link between infection and infarction? Ann Clin Res, 1988; 20(3): 151-153.

[33] Wareham L K, Southam H M, Poole R K. Do nitric oxide, carbon monoxide and hydrogen sulfide really qualify as 'gasotransmitters' in bacteria? Biochemical Society Transactions, 2018; 46(5): 1107-1118.

[34] Linden D R. Hydrogen sulfide signaling in the gastrointestinal tract. Antioxid Redox Signal, 2014; 20(5): 818-830.

[35] Lin $Y H$, Liu Y P, Lin Y C, et al. Characterization of the role of endogenous nitric oxide in myogenic vascular oscillations during coolingevoked hemodynamic perturbations of rats. Can J Physiol Pharmacol, 2017; 95(7): 803-810.

[36] Du X, Jin Z, Liu Z, et al. H2S persulfidated and increased kinase activity of MPK4 to response cold stress in arabidopsis. Front Mol Biosci, 2021; 8: 635470.

[37] Pankow D, Ponsold W. Effect of cold exposure on carbon monoxideinduced adaptive reactions in the rat. Zeitschrift fur Die Gesamte Hygiene und Ihre Grenzgebiete, 1984; 30(6): 330-331.

[38] Liu C, Yavar Z, Sun Q. Cardiovascular response to thermoregulatory challenges. Am J Physiol Heart Circ Physiol, 2015; 309(11): H1793-H1812.

[39] Ryti N R, Guo Y, Jaakkola J J. Global association of cold spells and adverse health effects: a systematic review and meta-analysis. Environmental Health Perspectives, 2016; 124(1): 12-22.

[40] Fares A. Winter cardiovascular diseases phenomenon. North Am J Med Sci, 2013; 5(4): 266-279.

[41] Ryti N R I, Mäkikyrö E M S, Antikainen H, et al. Risk of sudden cardiac death in relation to season-specific cold spells: a case-crossover study in Finland. BMJ Open, 2017; 7(11): e017398.

[42] Ikäheimo T M, Lehtinen T, Antikainen R, et al. Cold-related cardiorespiratory symptoms among subjects with and without hypertension: the National FINRISK Study 2002. Eur J Public Health, 2014; 24(2): 237-243.

[43] Nagarajan V, Fonarow G C, Ju C, et al. Seasonal and circadian variations of acute myocardial infarction: Findings from the Get With The Guidelines-Coronary Artery Disease (GWTG-CAD) program. Am Heart J, 2017; 189: 85-93.

[44] Libby P, Ridker P M, Hansson G K. Progress and challenges in translating the biology of atherosclerosis. Nature, 2011; 473(7347): 317325.

[45] Braun R C. A natural-history study of coronary disease. The New England Journal of Medicine, 2011; 364(15): 1469.

[46] Wolf K, Schneider A, Breitner S, et al. Air temperature and the occurrence of myocardial infarction in Augsburg, Germany. Circulation, 2009; 120(9): 735-742.

[47] Ikäheimo T M. Cardiovascular diseases, cold exposure and exercise. Temperature (Austin, Tex), 2018; 5(2): 123-146.

[48] Matthews E L, Greaney J L, Wenner M M. Rapid onset pressor response to exercise in young women with a family history of hypertension. Experimental Physiology, 2017; 102(9): 1092-1099.

[49] Hintsala $\mathrm{H}$, Kandelberg A, Herzig K H, et al. Central aortic blood pressure of hypertensive men during short-term cold exposure. Am J Hypertens, 2014; 27(5): 656-664.

[50] Fregly M J, Rossi F, Sun Z, et al. Effect of chronic treatment with prazosin and L-arginine on the elevation of blood pressure during cold exposure. Pharmacology, 1994; 49(6): 351-362.

[51] Sun Z, Cade R, Katovich M J, et al. Body fluid distribution in rats with cold-induced hypertension. Physiol Behav, 1999; 65(4-5): 879-884.

[52] Sun Z, Cade R, Morales C. Role of central angiotensin II receptors in cold-induced hypertension. Am J Hypertens, 2002; 15(1 Pt 1): 85-92.

[53] Bell A W, Thompson G E. The effects of acute cold exposure and feeding on the circulation of the young ox (Bos taurus), with special reference to the hind leg. Res Vet Sci, 1974; 17(3): 384-389.

[54] Van B P, Fregly M J, Rossi F, et al. The effect of intermittent exposure to cold on the development of hypertension in the rat. Am J Hypertens, 1992; 5(8): 548-555.

[55] Barney C C, Katovich M J, Fregly M J, et al. Changes in betaadrenergic responsiveness of rats during chronic cold exposure. J Appl Physiol, 1980; 49(6): 923-929.

[56] Sun H J. Current opinion for hypertension in renal fibrosis. Adv Exp Med Biol, 2019; 1165: 37-47.

[57] Zhang J R, Sun H J. Extracellular vesicle-mediated vascular cell communications in hypertension: mechanism insights and therapeutic potential of ncRNAs. Cardiovasc Drugs Ther, 2020. Online ahead of print.

[58] Xiong $\mathrm{Y}$, Xiong $\mathrm{Y}$, Zhu $\mathrm{P}$, et al. The role of gut microbiota in hypertension pathogenesis and the efficacy of antihypertensive drugs. Curr Hypertens Rep, 2021; 23(8): 40.

[59] Sun Z, Cade R, Zhang Z, et al. Angiotensinogen gene knockout delays and attenuates cold-induced hypertension. Hypertension (Dallas, Tex: 1979), 2003; 41(2): 322-327.

[60] Chen P G, Sun Z. AAV Delivery of endothelin-1 shRNA attenuates cold-induced hypertension. Human Gene Therapy, 2017; 28(2): 190-199. [61] Cheema A N, Yanagawa B, Verma S, et al. Myocardial infarction with nonobstructive coronary artery disease (MINOCA): a review of pathophysiology and management. Curr Opin Cardiol, 2021; 36(5): 589596.

[62] Dong M, Yang X, Lim S, et al. Cold exposure promotes atherosclerotic plaque growth and instability via UCP1-dependent lipolysis. Cell Metab, 2013; 18(1): 118-129.

[63] Areskog N H, Lassvik C. Angina pectoris in the cold. Arctic Med Res, 1988; 47(Suppl 1): 269-271.

[64] Cheng J, Su H, Xu Z, et al. Extreme temperature exposure and acute myocardial infarction: Elevated risk within hours? Environ Res, 2021; 202: 111691.

[65] Ryti N R, Mäkikyrö E M, Antikainen $\mathrm{H}$, et al. Cold spells and ischaemic sudden cardiac death: effect modification by prior diagnosis of ischaemic heart disease and cardioprotective medication. Sci Rep, 2017; 7: 41060 .

[66] Mudge G H, Grossman W, Mills R M, et al. Reflex increase in coronary vascular resistance in patients with ischemic heart disease. Ne Engl J Med, 1976; 295(24): 1333-1337.

[67] Zeiher A M, Drexler H, Wollschlaeger $\mathrm{H}$, et al. Coronary vasomotion in response to sympathetic stimulation in humans: importance of the functional integrity of the endothelium. J Am Coll Cardiol, 1989; 14(5): 1181-1190.

[68] Sevre K, Rostrup M. Blood pressure and heart rate responses to cold pressor test in patients admitted to hospital due to chest pain. Blood Press, 1999; 8(2): 110-113.

[69] Mcmurray J J, Adamopoulos S, Anker S D, et al. ESC Guidelines 
for the diagnosis and treatment of acute and chronic heart failure 2012: the task force for the diagnosis and treatment of acute and chronic heart failure 2012 of the european society of cardiology. Developed in collaboration with the Heart Failure Association (HFA) of the ESC. Eur Heart J, 2012; 33(14): 1787-1847.

[70] Budts W, Roos J, R Dle H T, et al. Treatment of heart failure in adult congenital heart disease: a position paper of the Working Group of Grown-Up Congenital Heart Disease and the Heart Failure Association of the European Society of Cardiology. Eur Heart J, 2016; 37(18): 14191427.

[71] Ponikowski P, Voors A A, Anker S D, et al. 2016 ESC Guidelines for the diagnosis and treatment of acute and chronic heart failure: The Task Force for the diagnosis and treatment of acute and chronic heart failure of the European Society of Cardiology (ESC)Developed with the special contribution of the Heart Failure Association (HFA) of the ESC. Eur Heart J, 2016; 37(27): 2129-2200.

[72] Forcey D S, Fitzgerald M P. 'Cold and lonely': emergency presentations of patients with hypothermia to a large Australian health network. Intern Med J, 2020; 50(1): 54-60.

[73] Radtke T, Poerschke D, Wilhelm M, et al. Acute effects of Finnish sauna and cold-water immersion on haemodynamic variables and autonomic nervous system activity in patients with heart failure. Eur J Prev Cardiol, 2016; 23(6): 593-601.

[74] Huang $Y Q$, Jin $H F$, Zhang $H$, et al. Interaction among hydrogen sulfide and other gasotransmitters in mammalian physiology and pathophysiology. Adv Exp Med Biol, 2021; 1315: 205-236.

[75] Guerra D D, Hurt K J. Gasotransmitters in pregnancy: from conception to uterine involution. Biol Reprod, 2019; 101(1): 4-25.

[76] Wang R. Gasotransmitters: growing pains and joys. Trends Biochem Sci, 2014; 39(5): 227-232.

[77] Kajimura M, Fukuda R, Bateman R M, et al. Interactions of multiple gas-transducing systems: hallmarks and uncertainties of $\mathrm{CO}, \mathrm{NO}$, and H2S gas biology. Antioxid Redox Signal, 2010; 13(2): 157-192.

[78] Polhemus D J, Lefer D J. Emergence of hydrogen sulfide as an endogenous gaseous signaling molecule in cardiovascular disease. Circ Res, 2014; 114(4): 730-737.

[79] Lancaster J R. Historical origins of the discovery of mammalian nitric oxide (nitrogen monoxide) production/physiology/pathophysiology. Biochem Pharmacol, 2020; 176: 113793.

[80] Durante W. Carbon monoxide and bile pigments: surprising mediators of vascular function. Vascular Medicine, 2002; 7(3): 195-202.

[81] Kimura $\mathrm{H}$. The physiological role of hydrogen sulfide and beyond. Nitric Oxide, 2014; 41: 4-10.

[82] Hsu C N, Tain Y L. Gasotransmitters for the therapeutic prevention of hypertension and kidney disease. Int J Mol Sci, 2021, 22(15): 7808.

[83] Rengarajan A, Msuro A K, Boeldt D S. Maternal disease and gasotransmitters. Nitric Oxide, 2020; 96: 1-12.

[84] Tran Q K, Leonard J, Black D J, et al. Effects of combined phosphorylation at Ser-617 and Ser-1179 in endothelial nitric-oxide synthase on $\mathrm{EC} 50(\mathrm{Ca} 2+)$ values for calmodulin binding and enzyme activation. J Biol Chem, 2009; 284(18): 11892-11899.

[85] Boeldt D S, Yi F X, Bird I M. eNOS activation and NO function: pregnancy adaptive programming of capacitative entry responses alters nitric oxide (NO) output in vascular endothelium--new insights into eNOS regulation through adaptive cell signaling. J Endocrinol, 2011; 210(3): 243-258.
[86] Förstermann U, Sessa W C. Nitric oxide synthases: regulation and function. Eur Heart J, 2012; 33(7): 829-837, 37a-37d.

[87] Rochette L, Lorin J, Zeller M, et al. Nitric oxide synthase inhibition and oxidative stress in cardiovascular diseases: possible therapeutic targets? Pharmacol Ther, 2013; 140(3): 239-257.

[88] Francis S H, Busch J L, Corbin J D, et al. cGMP-dependent protein kinases and cGMP phosphodiesterases in nitric oxide and cGMP action. Pharmacol Rev, 2010; 62(3): 525-563.

[89] Wurm C J, Lindermayr C. Nitric oxide signaling in the plant nucleus: the function of nitric oxide in chromatin modulation and transcription. $J$ Exp Bot, 2021; 72(3): 808-818.

[90] Keszler A, Zhang Y, Hogg N. Reaction between nitric oxide, glutathione, and oxygen in the presence and absence of protein: How are S-nitrosothiols formed? Free Radic Biol Med, 2010; 48(1): 55-64.

[91] Tenhunen R, Marver H S, Schmid R. The enzymatic conversion of heme to bilirubin by microsomal heme oxygenase. Proc Natl Acad Sci U S A, 1968; 61(2): 748-755.

[92] Applegate LA, Luscher P, Tyrrell R M. Induction of heme oxygenase: a general response to oxidant stress in cultured mammalian cells. Cancer Res, 1991; 51(3): 974-978.

[93] Ryter S W, Morse D, Choi A M. Carbon monoxide: to boldly go where $\mathrm{NO}$ has gone before. Science's STKE: signal transduction knowledge environment, 2004; 2004(230): Re6.

[94] Mccoubrey W K, Huang T J, Maines M D. Isolation and characterization of a cDNA from the rat brain that encodes hemoprotein heme oxygenase-3. Eur J Biochem, 1997; 247(2): 725-732.

[95] Maines M D. Heme oxygenase: function, multiplicity, regulatory mechanisms, and clinical applications. FASEB J, 1988; 2(10): 25572568.

[96] Chen Y, Zhang F, Yin J, et al. Protective mechanisms of hydrogen sulfide in myocardial ischemia. J Cell Physiol, 2020; 235(12): 9059-9070. [97] Wen $Y$ D, Wang H, Zhu Y Z. The drug developments of hydrogen sulfide on cardiovascular disease. Oxid Med Cell Longev, 2018; 2018 : 4010395.

[98] Sun H J, Wu Z Y, Nie X W, et al. The Role of H2S in the Metabolism of Glucose and Lipids. Adv Exp Med Biol, 2021; 1315: 51-66.

[99] Sun H J, Wu Z Y, Nie X W, et al. Implications of hydrogen sulfide in liver pathophysiology: mechanistic insights and therapeutic potential. J Adv Res, 2021; 27: 127-135.

[100] Sun H J, Wu Z Y, Nie X W, et al. Role of endothelial dysfunction in cardiovascular diseases: the link between inflammation and hydrogen sulfide. Front Pharmacol, 2019; 10: 1568.

[101] Kanagy N L, Szabo C, Papapetropoulos A. Vascular biology of hydrogen sulfide. Am J Physiol Cell Physiol, 2017; 312(5): c537-c549.

[102] Sun H J, Wu Z Y, Nie X W, et al. Role of hydrogen sulfide and polysulfides in neurological diseases: focus on protein S-persulfidation. Current Neuropharmacology, 2021; 19(6): 868-884.

[103] Zhao Q, Gu D, Lu F, et al. Blood pressure reactivity to the cold pressor test predicts hypertension among Chinese adults: the GenSalt study. Am J Hypertens, 2015; 28(11): 1347-1354.

[104] Menkes M S, Matthews K A, Krantz D S, et al. Cardiovascular reactivity to the cold pressor test as a predictor of hypertension. Hypertension (Dallas, Tex : 1979), 1989; 14(5): 524-530.

[105] Psrk J, Middlekauff H R, Campese V M. Abnormal sympathetic reactivity to the cold pressor test in overweight humans. Am J Hypertens, 2012; 25(12): 1236-1241. 
[106] Grassi G, Biffi A, Seravalle G, et al. Sympathetic neural overdrive in the obese and overweight state. Hypertension, 2019; 74(2): 349-358.

[107] Manou S V, Goodwin C D, Patterson T, et al. The effects of cold and exercise on the cardiovascular system. Heart (British Cardiac Society), 2015; 101(10): 808-820.

[108] Ochiai M, Hayashi T, Morita M, et al. Short-term effects of L-citrulline supplementation on arterial stiffness in middle-aged men. Int $\mathrm{J}$ Cardiol, 2012; 155(2): 257-261.

[109] Figueroa A, Trivino J A, Sanchez M A, et al. Oral L-citrulline supplementation attenuates blood pressure response to cold pressor test in young men. Am J Hypertens, 2010; 23(1): 12-16.

[110] Figueroa A, Alvarez A S, Jaime S J, et al. I-Citrulline supplementation attenuates blood pressure, wave reflection and arterial stiffness responses to metaboreflex and cold stress in overweight men. Br J Nutr, 2016; 116(2): 279-285.

[111] Shechtman O, Fregly M J, Van B P, et al. Prevention of cold-induced increase in blood pressure of rats by captopril. Hypertension (Dallas, Tex : 1979), 1991; 17(6 Pt 1): 763-770.

[112] Skutecki R, Jalali R, Dragańska E, et al. UTCl as a biometeorological tool in the assessment of cold-induced stress as a risk factor for hypertension. Sci Total Environ, 2019; 688: 970-975.

[113] Roukoyatkina N I, Chefer S I, Rifkind J, et al. Cold acclimationinduced increase of systolic blood pressure in rats is associated with volume expansion. Am J Hypertens, 1999; 12 (1 Pt 1): 54-62.

[114] Peng J F, Phillips M I. Opposite regulation of brain angiotensin type 1 and type 2 receptors in cold-induced hypertension. Regul Pept, 2001; 97(2-3): 91-102.

[115] Cárnio E C, Branco L G. Participation of the nitric oxide pathway in cold-induced hypertension. Life Sci, 1997; 60(21): 1875-1880.

[116] Shi H M, He L H, Zhang $Y$, et al. Changes of nitric oxide and nitric-oxide synthase in the development of cold-induced hypertension. Zhonghua Lao Dong Wei Sheng Zhi Ye Bing Za Zhi, 2007; 25(4): 197199.

[117] Zhang S, Zhang Y, Ahsan M Z, et al. Atorvastatin attenuates coldinduced hypertension by preventing gut barrier injury. J Cardiovasc Pharmacol 2019; 74(2): 143-151.

[118] Zhu Z, Zhu S, Zhu J, et al. Endothelial dysfunction in cold-induced hypertensive rats. Am J Hypertens, 2002; 15(2 Pt 1): 176-180.

[119] Qian L, Pan N, Gong J. Change of NOS activity in hypoxia and coldinduced blood vessels damage and its biological significance. Zhonghua Yu Fang Yi Xue Za Zhi, 2001; 35(1): 57-60.

[120] Sun C F, Wang S G, Peng Y G, et al. Intervention of systolic pressure and left ventricular hypertrophy in rats under cold stress. Zhonghua Lao Dong Wei Sheng Zhi Ye Bing Za Zhi, 2016; 34(6): 438443.

[121] O'brien C. Reproducibility of the cold-induced vasodilation response in the human finger. J Appl Physiol, 2005; 98(4): 1334-1340.

[122] Daanen H A. Finger cold-induced vasodilation: a review. European J Appl Physiol, 2003; 89(5): 411-426.

[123] Aubdool A A, Graepel R, Kodji X, et al. TRPA1 is essential for the vascular response to environmental cold exposure. Nature Commun, 2014; 5: 5732.

[124] Corson M A, James N L, Latta S E, et al. Phosphorylation of endothelial nitric oxide synthase in response to fluid shear stress. Circ Res, 1996; 79(5): 984-991.

[125] Boo Y C, Sorescu G, Boyd N, et al. Shear stress stimulates phosphorylation of endothelial nitric-oxide synthase at Ser1179 by Aktindependent mechanisms: role of protein kinase A. J Biol Chem, 2002; 277(5): 3388-3396.

[126] Binti I K, Kawawaki N, Ueyama K, et al. Effects of cold exposure and shear stress on endothelial nitric oxide synthase activation. Biochem Biophys Res Commun, 2011; 412(2): 318-322.

[127] Sun Z, Fregly M J, Cade J R. Effect of renal denervation on elevation of blood pressure in cold-exposed rats. Can J Physiol Pharmacol, 1995; 73(1): 72-78.

[128] Sun Z, Cade J R, Fregly M J. Cold-induced hypertension. A model of mineralocorticoid-induced hypertension. Ann N Y Acad Sci, 1997; 813: 682-688.

[129] Baron A, Riesselmann A, Fregly M J. Effect of chronic treatment with clonidine and spironolactone on cold-induced elevation of blood pressure. Pharmacology, 1991; 43(4): 173-186.

[130] Peng J F, Kimura B, Fregly M J, et al. Reduction of cold-induced hypertension by antisense oligodeoxynucleotides to angiotensinogen mRNA and AT1-receptor mRNA in brain and blood. Hypertension (Dallas, Tex : 1979), 1998; 31(6): 1317-1323.

[131] Sun Z, Wang X, Wood C E, et al. Genetic AT1A receptor deficiency attenuates cold-induced hypertension. American Journal of Physiology Regulatory, Integrative and Comparative Physiology, 2005; 288(2): R433-R439.

[132] Wang X, Cade R, Sun Z. Human eNOS gene delivery attenuates cold-induced elevation of blood pressure in rats. Am J Physiol Heart Circ Physiol, 2005; 289(3): H1161-1168.

[133] Al-ayadhi L Y, Korish A A, Al-tuwaiji A S. The effect of vitamin E, $\mathrm{L}$-arginine, $\mathrm{N}$-nitro $\mathrm{L}$-arginine methyl ester and forskolin on endocrine and metabolic changes of rats exposed to acute cold stress. Saudi Med J, 2006; 27(1): 17-22.

[134] Korac A, Buzadzic B, Petrovic V, et al. The role of nitric oxide in remodeling of capillary network in rat interscapular brown adipose tissue after long-term cold acclimation. Histol Histopathol, 2008; 23(4): 441-450. [135] Wu L, Wang R. Carbon monoxide: endogenous production, physiological functions, and pharmacological applications. Pharmacol Rev, 2005; 57(4): 585-630.

[136] Ryter S W, Alam J, Choi A M. Heme oxygenase-1/carbon monoxide: from basic science to therapeutic applications. Physiol Rev, 2006; 86(2): 583-650.

[137] Kim H H, Choi S. Therapeutic aspects of carbon monoxide in cardiovascular disease. Int J Mol Sci, 2018, 19(8): 2381.

[138] Gautier H, Murariu C, Bonora M. Ventilatory and metabolic responses to ambient hypoxia or hypercapnia in rats exposed to $\mathrm{CO}$ hypoxia. J Appl Physiol, 1997; 83(1): 253-261.

[139] Fahey P J, Utell M J, Condemi J J, et al. Raynaud's phenomenon of the lung. Am J Med, 1984; 76(2): 263-269.

[140] Barr W G, Fahey P J. Reduction of pulmonary capillary blood volume following cold exposure in patients with Raynaud's phenomenon. Chest, 1988; 94(6): 1195-1199.

[141] Balestrasse K B, Tomaro M L, Batlle A, et al. The role of 5 -aminolevulinic acid in the response to cold stress in soybean plants. Phytochemistry, 2010; 71(17-18): 2038-2045.

[142] Broder J, Mehrotra A, Tintinalli J. Injuries from the 2002 North Carolina ice storm, and strategies for prevention. Injury, 2005; 36(1): 2126.

[143] Oh B J, Im Y G, Park E, et al. Treatment of acute carbon monoxide 
poisoning with induced hypothermia. Clin Exp Emerg Med, 2016; 3(2): 100-104.

[144] Park E, Ahn J, Min Y G, et al. The usefulness of the serum s100b protein for predicting delayed neurological sequelae in acute carbon monoxide poisoning. Clin Toxicol (Phila), 2012; 50(3): 183-188.

[145] Jung Y S, Lee J S, Min Y G, et al. Carbon monoxide-induced cardiomyopathy. Circ J, 2014; 78(6): 1437-1444.

[146] Motterlini R, Otterbein L E. The therapeutic potential of carbon monoxide. Nat Rev Drug Discov, 2010; 9(9): 728-743.

[147] Testai L, Citi V, Martelli A, et al. Role of hydrogen sulfide in cardiovascular ageing. Pharmacological Research, 2020; 160: 105125.

[148] Zhang H, Bai Z, Zhu L, et al. Hydrogen sulfide donors: Therapeutic potential in anti-atherosclerosis. Eur J Med Chem, 2020; 205: 112665.

[149] Teoh J P, Li X, Simoncini T, et al. Estrogen-Mediated Gaseous Signaling Molecules in Cardiovascular Disease. Trends Endocrinol Metab, 2020; 31(10): 773-784.

[150] Gorini F, Bustaffa E, Chatzianagnostou K, et al. Hydrogen sulfide and cardiovascular disease: Doubts, clues, and interpretation difficulties from studies in geothermal areas. Sci Total Environ, 2020; 743: 140818.

[151] Luo W, Gui D D, Yan B J, et al. Hydrogen Sulfide Switch Phenomenon Regulating Autophagy in Cardiovascular Diseases. Cardiovasc Drugs Ther, 2020; 34(1): 113-121.

[152] Rose P, Moore P K, Zhu Y Z. Garlic and gaseous mediators. Trends in Pharmacological Sciences, 2018; 39(7): 624-634.

[153] Pan L L, Qin M, Liu X H, et al. The role of hydrogen sulfide on cardiovascular homeostasis: an overview with update on immunomodulation. Front Pharmacol, 2017; 8: 686.

[154] Wang M J, Cai W J, Zhu Y C. Hydrogen sulphide in cardiovascular system: A cascade from interaction between sulphur atoms and signalling molecules. Life Sci, 2016; 153: 188-197.

[155] Li Z, Polhemus D J, Lefer D J. Evolution of hydrogen sulfide therapeutics to treat cardiovascular disease. Circ Res, 2018; 123(5): 590-600.

[156] Yu X H, Cui L B, Wu K, et al. Hydrogen sulfide as a potent cardiovascular protective agent. Clin Chim Acta, 2014; 437: 78-87.

[157] Minasian S M, Galagudza M M, Dmitriev Y V, et al. Preservation of the donor heart: from basic science to clinical studies. Interact Cardiovasc Thorac Surg, 2015; 20(4): 510-519.

[158] Zhu C, Su Y, Juriasingani S, et al. Supplementing preservation solution with mitochondria-targeted $\mathrm{H}(2) \mathrm{S}$ don or AP39 protects cardiac grafts from prolonged cold ischemia-reperfusion injury in heart transplantation. Am J Transplant, 2019; 19(11): 3139-3148.

[159] Lobb I, Jiang J, Lian D, et al. Hydrogen sulfide protects renal grafts against prolonged cold ischemia-reperfusion injury via specific mitochondrial actions. Am J Transplant, 2017; 17(2): 341-352.

[160] Juriasingani S, Akbari M, Chan J Y, et al. H2S supplementation: a novel method for successful organ preservation at subnormothermic temperatures. Nitric Oxide, 2018; 81: 57-66.

[161] Dugbartey G J, Bouma H R, Saha M N, et al. A hibernation-like state for transplantable organs: is hydrogen sulfide therapy the future of organ preservation? Antioxid Redox Signal, 2018; 28(16): 1503-1515.

[162] Citi V, Martelli A, Gorica E, et al. Role of hydrogen sulfide in endothelial dysfunction: Pathophysiology and therapeutic approaches. J Adv Res, 2021; 27: 99-113.

[163] Lv B, Chen S, Tang C, et al. Hydrogen sulfide and vascular regulation-An update. J Adv Res, 2021; 27: 85-97.

[164] Dong E, Kiss L. The potential role of hydrogen sulfide in the regulation of cerebrovascular tone. Biomolecules, 2020; 10(12): 1685.

[165] Graham T E. Thermal, metabolic, and cardiovascular changes in men and women during cold stress. Med Sci Sports Exerc, 1988; 20(5 Suppl): S185-S192.

[166] Achebak H, Devolder D, Ballester J. Trends in temperature-related age-specific and sex-specific mortality from cardiovascular diseases in Spain: a national time-series analysis. Lancet Planet Health, 2019; 3(7): e297-e306.

[167] Mugele H, Oliver S J. Integrative crosstalk between hypoxia and the cold: Old data and new opportunities. Exp Physiol, 2021; 106(1): 350358.

[168] Johoston C E, White M D, Wu M, et al. Eucapnic hypoxia lowers human cold thermoregulatory response thresholds and accelerates core cooling. J Appl Physiol, 1996; 80(2): 422-429. 